\title{
PENGARUH PSYCHOLOGICAL CAPITAL DAN KEPUASAN KERJA TERHADAP KINERJA KARYAWAN YANG DIMEDIASI OLEH WORK ENGAGEMENT PADA KARYAWAN KANTOR PUSAT PT BG
}

\author{
Kevin Jonathan \\ Program Studi Magister Manajemen Universitas Tarumanagara \\ mrkevinjonathan@gmail.com \\ Rezi Erdiansyah \\ Program Studi Magister Manajemen Universitas Tarumanagara
}

Masuk : 05-12-2020, revisi : 23-12-2020, diterima untuk diterbitkan : 23-12-2020

\begin{abstract}
In the era of globalization that is continuously developing, organizations are required to be able to adapt themselves more quickly to changes and challenges that occur. These changes can be in various ways that directly or indirectly affect the survival and performance of the organization in general. To be able to compete globally, organizations need to be supported by superior human resources in terms of job satisfaction, psychological capital, work engagement, as well as performance. One of the companies in the food and beverage sector that have been established since 1960, namely PT BG is a family company that initially only had one store in the West Jakarta area and to date has 60 stores spread across Jabodetabek, Karawang, Cikarang, Surabaya, and Bali. To improve the quality of these products and services, it is necessary to be supported by a professional, competent workforce who also has good performance to support the achievement of the company's business. Data obtained from questionnaires were distributed via a google form. The sample used in this study was 132 respondents with the help of SmartPLS software. The results showed that work engagement mediated the effect of psychological capital on employee performance in a positive direction and work engagement mediated the effect of job satisfaction on employee performance in a positive direction.
\end{abstract}

Keywords: Job Satisfaction, Psychological Capital, Work Engagement, Employee Perfomance, Strategic Human Resources Management

Abstrak: Di era globalisasi yang terus menerus berkembang ini, organisasi dituntut untuk dapat lebih cepat dalam menyesuaikan diri terhadap perubahan-perubahan maupun tantangantantangan yang terjadi. Perubahan-perubahan tersebut bisa dalam berbagai hal yang secara langsung maupun tidak langsung berdampak pada kelangsungan hidup maupun kinerja organisasi secara umum. Untuk dapat tepat bersaing secara global, organisasi perlu didukung oleh sumber daya manusia yang unggul dari segi kepuasan kerja, psychological capital, work engagement, maupun kinerja yang handal. Salah satu perusahaan di bidang makanan dan minuman yang telah berdiri sejak tahun 1960, yaitu PT BG merupakan perusahaan keluarga yang pada awalnya hanya memiliki satu store yang terdapat di daerah Jakarta Barat dan sampai pada saat ini telah memiliki 60 store yang tersebar di Jabodetabek, Karawang, Cikarang, Surabaya, dan Bali. Tentu untuk meningkatkan kualitas produk dan layanan tersebut perlu didukung oleh tenaga kerja yang profesional, kompeten, dan juga memiliki performa yang baik untuk menunjang pencapaian bisnis perusahaan. Data diperoleh dari kuesioner yang disebar melalui google form. Sampel yang digunakan dalam penelitian ini sebanyak 132 responden dengan bantuan software SmartPLS. Hasil penelitian menunjukkan bahwa work engagement memediasi pengaruh psychological capital terhadap kinerja karyawan dengan arah yang positif dan work engagement memediasi pengaruh kepuasan kerja terhadap kinerja karyawan dengan arah yang positif. 
Kata Kunci: Kepuasan Kerja, Psychological Capital, Work Engagement, Kinerja Karyawan, Strategi Manajemen Sumberdaya Manusia

\section{PENDAHULUAN}

Di era globalisasi yang terus menerus berkembang ini, organisasi dituntut untuk dapat lebih cepat dalam menyesuaikan diri terhadap perubahan-perubahan maupun tantangantantangan yang terjadi. Perubahan-perubahan tersebut bisa dalam berbagai hal yang secara langsung maupun tidak langsung berdampak pada kelangsungan hidup maupun kinerja organisasi secara umum.

Untuk dapat tepat bersaing secara global, organisasi perlu didukung oleh sumber daya manusia yang unggul dari segi kepuasan kerja, psychological capital, work engagement, maupun kinerja yang handal. Keberhasilan suatu organisasi baik besar maupun kecil bukan semata -mata ditentukan oleh sumber daya alam yang tersedia, akan tetapi banyak ditentukan oleh kualitas sumber daya manusia (SDM) yang berperan merencanakan, melaksanakan dan mengendalikan organisasi yang bersangkutan (Bukit et al., 2017). Sumber daya manusia merupakan sumber daya yang vital bagi organisasi, dan juga merupakan kontributor penting bagi mengungguli persaingan yang kompetitif. Investasi pada sumber daya manusia merupakan hal yang krusial bagi kesuksesan organisasi dalam lingkungan bisnis yang penuh dengan persaingan (Luthans et al., 2007).

Terkait dengan perlunya penelitian yang dilakukan pada variabel-variabel tersebut, industri yang saat ini sedang berkembang pesat yaitu industri makanan. Bursa Efek Indonesia menampilkan data dimana industri makanan dan minuman merupakan industri dengan nilai rata-rata laju pertumbuhan PDB tertinggi di Indonesia tahun 2016-2018 yaitu mencapai 8,49 persen. Pertumbuhan laju tersebut sejalan dengan perkembangan industri atau usaha atau perusahaan subsektor makanan dan minuman. Perusahaan yang bergerak pada subsektor makanan dan minuman sebanyak 26 perusahaan tahun 2019 (Bursa Efek Indonesia, 2019).

Dengan perkembangan industri subsektor makanan dan minuman yang berlangsung dengan pesat, perusahaan di dalam industri inipun perlu lebih meningkatkan daya saing dengan perusahaan-perusahaan lain di bidang industri yang sama. Salah satu perusahaan di bidang makanan dan minuman yang telah berdiri sejak tahun 1960, yaitu PT BG merupakan perusahaan keluarga yang pada awalnya hanya memiliki satu store yang terdapat di daerah Jakarta Barat dan sampai pada saat ini telah memiliki 60 store yang tersebar di Jabodetabek, Karawang, Cikarang, Surabaya, dan Bali. Seiring dengan berjalannya waktu dimana setiap tahun bermunculan pesaing-pesaing baru dengan subsektor yang sama, PT BG terus menerus meningkatkan kualitas layanan maupun produk yang ditawarkan. Tentu untuk meningkatkan kualitas produk dan layanan tersebut perlu didukung oleh tenaga kerja yang profesional, kompeten, dan juga memiliki performa yang baik untuk menunjang pencapaian bisnis perusahaan. Kinerja karyawan tersebut perlu untuk terus dipantau dan dimonitor selama periode tertentu untuk memastikan bahwal hasil yang didapat sesuai dengan tujuan maupun target yang telah ditentukan. Melalui data yang peneliti dapatkan dari data internal perusahaan. Divisi dengan rata-rata nilai penilaian kinerja tertinggi ada pada divisi FAST (Finance, Accounting, dan Information Technology), sedangkan rata-rata nilai penilaian kinerja terendah ada pada divisi Sumber Daya Manusia. Hal yang menarik untuk dapat diteliti adalah bahwa selisih yang cukup jauh dari hasil rata-rata terendah dan tertinggi dari kedua divisi tersebut telah terjadi selama 3 tahun (6 periode penilaian kinerja).

\section{Tujuan Penelitian}

a. Untuk mengetahui pengaruh psychological capital terhadap kinerja karyawan yang dimediasi oleh work engagement pada karyawan PT BG.

b. Untuk mengetahui pengaruh kepuasan kerja terhadap kinerja karyawan yang dimediasi oleh work engagement pada karyawan PT BG.

c. Untuk mengetahui pengaruh psychological capital terhadap kinerja karyawan PT BG. 
d. Untuk mengetahui pengaruh kepuasan kerja terhadap kinerja karyawan PT BG.

e. Untuk mengetahui pengaruh work engagement terhadap kinerja karyawan PT BG.

\section{TINJAUAN PUSTAKA}

\section{Psychological Capital}

Definisi Psychological Capital (PsyCap) menurut Luthans, et al. (2007) adalah "PsyCap is an individual's positive psychological state of development and is characterized by : (1) having confidence (self-efficacy) to take on and put in te necessary effort to succeed at challenging tasks; (2) making a positive attribution (optimism) about succeeding now and in the future; (3) persevering toward goals and, when necessary, redirecting paths to goals (hope) in order to succeed; and (4) when beset by problem and adversity, sustaining and bouncing back and even beyond (resiliency) to attain success.

\section{Kepuasan Kerja}

Menurut Johlke dan Duhan (2000), Parish et al. (2008) serta Homburg dan Stock (2004), kepuasan kerja didefinisikan sebagai "as a pleasurable or positive emotional state resulting from a person's appraisal of his or her job or job experiences" jika diartikan berarti "sebagai sesuatu yang menyenangkan atau keadaan emosi positif yang dihasilkan dari penilaian seseorang terhadap pekerjaan atau pengalaman kerjanya" (Locke, 1976, p. 1300). Bettencourt dan Brown (1997) berpendapat bahwa kepuasan kerja merujuk pada "an employee's overall affective evaluation of the job situation" atau jika diartikan yaitu evaluasi afektif keseluruhan karyawan terhadap situasi pekerjaan.

Robbins (2017) dalam bukunya yang berjudul Organizational Behavior mendefinisikan kepuasan kerja sebagai " a positive feeling about one's job resulting from an evaluation of its characteristics" yang jika diterjemahkan ke dalam bahasa Indonesia yaitu perasaan positif tentang pekerjaan seseorang yang dihasilkan dari evaluasi karakteristiknya.

\section{Work Engagement}

Schaufeli et al. (2002) mendefinisikan work engagement sebagai "A positive, fulfilling, work-related state of mind that is characterized by vigor, dedication, and absorption." Dimensi yang ada dalam work engagement digambarkan melalui karakteristik-karakteristik tertentu sebagai berikut (Bakker et al., 2008):

1. Vigor dikarakteristikkan melalui tingginya tingkat energi dan resiliensi mental ketika bekerja, bersedia untuk memberi usaha pada pekerjaan, dan persisten dalam menghadapi kesulitan.

2. Dedication mengacu pada terlibat secara kuat terhadap pekerjaan, mengalami rasa signifikan, antusias, inspirasi, kebanggaan, dan tantangan.

3. Absorption dikarakteristikkan sebagai konsentrasi secara penuh dan senang dalam bekerja ditandai dengan waktu yang terasa cepat berlalu dan sulit untuk memisahkan diri dari pekerjaan (Schaufeli et al., 2002).

\section{Kinerja Karyawan}

Campbell et al. (1993) mendefinisikan kinerja/performance sebagai kinerja yang terdiri dari perilaku di mana karyawan benar-benar terlibat dan dapat diamati perilakunya. Definisi lain yang datang dari Moorhead dan Griffin (1999), kinerja merupakan semua rangkaian total perilaku terkait pekerjaan yang diharapkan organisasi dari individu untuk ditampilkan. Campbell et al. (1990) mendefinisikan kinerja sebagai perilaku atau aktivitas yang berorientasi pada tujuan dan sasaran organisasi. Menurut Rotundo dan Sackett (2002), kinerja karyawan meliputi dimensi Task Performance, Contextual Performance, dan Counterproductive Work Behavior. 


\section{METODOLOGI PENELITIAN}

\section{Populasi dan Sampel}

Populasi merupakan seluruh elemen yang akan diteliti (Supranto, 2012). Keseluruhan elemen yang ada dalam penelitian ini adalah seluruh karyawan PT BG yang berjumlah 2.000 orang. Agar hasil penelitian dapat dipercaya, maka dibutuhkan sampel-sampel yang akan mewakili keseluruhan populasi. Sampel merupakan sebagian dari populasi. Sampling ialah cara pengumpulan data perkiraan atau estimate (menyimpulkan karakteristik populasi secara tidak pasti, mengandung unsur ketidakpastian) (Supranto, 2012).

Teknik pengambilan sampel yang digunakan adalah Quota Sampling, dimana pemilihan sampel kuota atau berdasarkan jumlah, merupakan pemilihan sampel dengan memilih sejumlah tertentu (kuota) unsur populasi menjadi anggota sampel dan paling mudah diperoleh seperti dikehendaki oleh peneliti (Silalahi, 2006). Salah satu metode yang digunakan untuk menentukan jumlah sampel adalah menggunakan rumus Slovin (Sevilla et al., 2007, p. 182) sebagai berikut:

Keterangan:

$$
\mathrm{n}=\text { Jumlah Sampel } \quad \mathrm{N}=\text { Jumlah Populasi } \quad \mathrm{d}^{2}=\text { Bond } \text { of errors }=5 \%=0,05
$$

Dengan perhitungan sebagai berikut: $\mathrm{n}=189 / 189(0.05)^{2}+1 \rightarrow \mathrm{n}=128$ orang

Berdasarkan perhitungan di atas, maka sampel yang diambil dalam penelitian ini adalah 128 orang karyawan. Penelitian ini menggunakan kuesioner yang dibagikan secara online, dengan menggunakan google form yang diisi oleh 132 orang karyawan yang terdiri dari 7 divisi. Terkait hal tersebut, pengolahan data dalam penelitian ini menggunakan bantuan software SmartPLS.

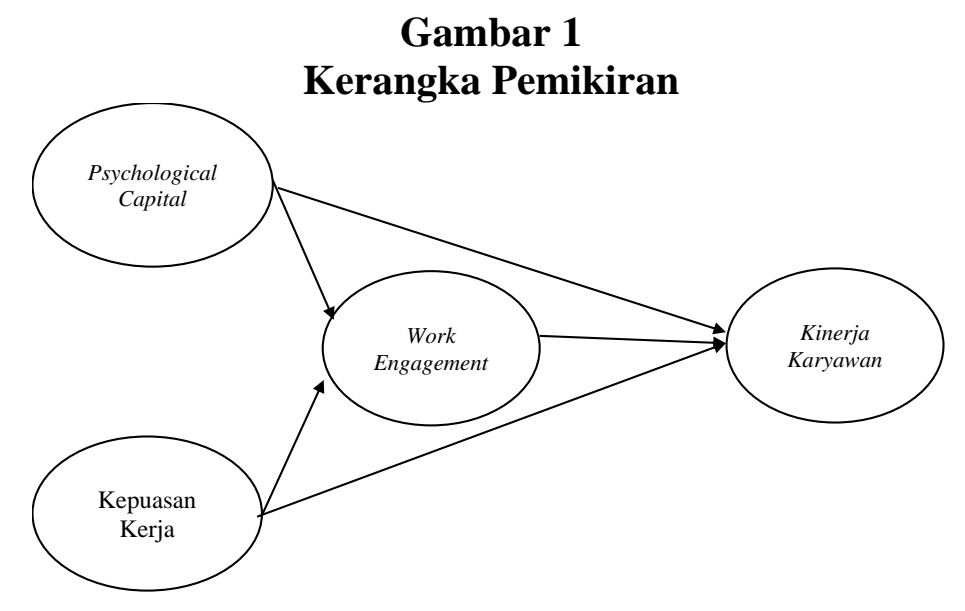

\section{HASIL DAN KESIMPULAN}

Hasil Penelitian

Untuk mengetahui pengaruh tidak langsung psychological capital terhadap kinerja karyawan yang di mediasi oleh work engagement, maka dapat dilihat pada tabel berikut:

$\mathrm{H}_{\mathrm{a}}$ : Ada pengaruh yang signifikan antara psychological capital terhadap kinerja karyawan melalui work engagement PT BG.

$\mathrm{H}_{\mathrm{o}}$ : Tidak ada pengaruh yang signifikan antara psychological capital terhadap kinerja karyawan melalui work engagement PT BG.

\section{Tabel 1}

Pengaruh Tidak Langsung dan Signifikansi Psychological Capital terhadap Kinerja Karyawan Dimediasi oleh Work Engagement

\begin{tabular}{|c|c|c|c|c|}
\hline & Original Sample & T Statistics & P Values & Keterangan \\
\hline $\begin{array}{c}\text { Psychological Capital -> Work } \\
\text { Engagement -> Kinerja Karyawan }\end{array}$ & $\mathbf{0 , 1 6 1}$ & $\mathbf{3 , 0 2 3}$ & $\mathbf{0 , 0 0 3}$ & Signifikan \\
\hline
\end{tabular}

Sumber: Data olah primer (2020) 
Hasil pengujian yang ditampilkan pada pada tabel 1 menunjukkan nilai path coefficient sebesar 0,161 signifikan pada $t$-statistic 3,023 > t-tabel 1,96 dan pada $P$-value $0,003<$ tingkat signifikansi 0,05. Dengan demikian, Hipotesis yang menyatakan bahwa terdapat pengaruh yang signifikan antara psychological capital terhadap kinerja karyawan melalui work engagement dapat diterima, dengan kata lain bahwa work engagement memediasi pengaruh psychological capital terhadap kinerja karyawan dengan arah yang positif.

Untuk mengetahui pengaruh tidak langsung kepuasan kerja terhadap kinerja karyawan yang di mediasi oleh work engagement, maka dapat dilihat pada tabel berikut:

$\mathrm{Ha}_{\mathrm{a}}$ : Ada pengaruh yang signifikan antara kepuasan kerja terhadap kinerja karyawan melalui work engagement PT BG.

Ho: Tidak ada pengaruh yang signifikan antara kepuasan kerja terhadap kinerja karyawan melalui work engagement PT BG.

\section{Tabel 2}

Pengaruh Tidak Langsung dan Signifikansi Kepuasan Kerja terhadap Kinerja Karyawan Dimediasi oleh Work Engagement

\begin{tabular}{|c|c|c|c|c|}
\hline & Original Sample & T Statistics & P Values & Keterangan \\
\hline $\begin{array}{c}\text { Kepuasan Kerja -> Work Engagement -> } \\
\text { Kinerja Karyawan }\end{array}$ & $\mathbf{0 , 2 4 9}$ & $\mathbf{3 , 4 2 1}$ & $\mathbf{0 , 0 0 1}$ & Signifikan \\
\hline
\end{tabular}

Sumber: Data olah primer (2020)

Hasil pengujian yang ditampilkan pada pada tabel 2 menunjukkan nilai path coefficient sebesar 0,249 signifikan pada $t$-statistic 3,421 > t-tabel 1,96 dan pada $P$-value $0,001<$ tingkat signifikansi 0,05. Dengan demikian, Hipotesis yang menyatakan bahwa terdapat pengaruh yang signifikan antara kepuasan kerja terhadap kinerja karyawan melalui work engagement dapat diterima, dengan kata lain bahwa work engagement mampu memediasi pengaruh kepuasan kerja terhadap kinerja karyawan dengan arah yang positif.

\section{DAFTAR PUSTAKA}

Bakker, A. B., Schaufeli, W. B., Leiter, M. P., \& Taris, T. W. (2008). Work engagement: An emerging concept in occupational health psychology. Work and Stress, 22(3), 187-200. https://doi.org/10.1080/02678370802393649

Bettencourt, L. A., \& Brown, S. W. (1997). Contact employees: Relationships among workplace fairness, job satisfaction and prosocial service behaviors. Journal of Retailing, 73(1), 39-61. https://doi.org/10.1016/S0022-4359(97)90014-2

Bukit, B., Malusa, T., \& Rahmat, A. (2017). Pengembangan sumber daya manusia: Teori, dimensi pengukuran dan implementasi dalam organisasi (1st ed.). Zahir Publishing.

Bursa Efek Indonesia. (2019). Profil Anggota Bursa. https://www.idx.co.id/anggota-bursadan-partisipan/profil-anggota-bursa/

Campbell, J. P., McCloy, R. A., Oppler, S. H., \& Sager, C. E. (1993). A theory of performance. In N. Schmitt \& W. C. Borman (Eds.), Personnel selection In organizations (pp. 35-70). Jossey-Bass.

Campbell, J. P., McHenry, J. J., \& Wise, L. L. (1990). Modeling job performance in a population of jobs. Personnel Psychology, 43(2), 313-575. https://doi.org/10.1111/j.1744-6570.1990.tb01561.x

Homburg, C., \& Stock, R. M. (2004). The link between salespeople's job satisfaction and customer satisfaction in a business-to-business context: A dyadic analysis. Journal of the Academy of Marketing Science, 32(2), 144-158.

https://doi.org/10.1177/0092070303261415

Johlke, M. C., \& Duhan, D. F. (2000). Supervisor communication practices and service employee job outcomes. Journal of Service Research, 3(2), 154-165. https://doi.org/10.1177/109467050032004 
Locke, E. A. (1976). The nature and causes of job satisfaction. In M. D. Dunnette (Ed.), Handbook of industrial and organizational psychology (1st ed., pp. 1297-1343). Rand McNally.

Luthans, F., Youssef, C. M., \& Avolio, B. J. (2007). Psychological capital: Developing the human competitive edge. In Psychological Capital: Developing the Human Competitive Edge. Oxford University Press. https://doi.org/10.1093/acprof:oso/9780195187526.001.0001

Moorhead, G., \& Griffin. (1999). Organizational behavioral : Managing people and organization (3rd ed.). Jaico Publishing House.

Parish, J. T., Cadwallader, S., \& Busch, P. (2008). Want to, need to, ought to: Employee commitment to organizational change. Journal of Organizational Change Management, 21(1), 32-52. https://doi.org/10.1108/09534810810847020

Robbins, S. P., \& Judge, T. A. (2017). Organizational behavior (15th ed.). Pearson Education, Inc.

Rotundo, M., \& Sackett, P. R. (2002). The relative importance of task, citizenship, and counterproductive performance to global ratings of job performance: a policy-capturing approach. The Journal of Applied Psychology, 87(1), 66-80. https://doi.org/10.1037/0021-9010.87.1.66

Schaufeli, W., Salanova, M., González-romá, V., \& Bakker, A. (2002). The measurement of engagement and burnout: A two sample confirmatory factor analytic approach. Journal of Happiness Studies, 3(1), 71-92. https://doi.org/10.1023/A:1015630930326

Sevilla, C. G., Ochave, J. A., Punsalan, T. G., \& Uriarte, G. G. (2007). Research methods. Rex Printing Company.

Silalahi, U. (2006). Metode penelitian sosial (1st ed.). Unpar Press.

Supranto. (2012). Metode riset aplikasinya dalam pemasaran. PT Rineka Cipta. 